\title{
Renin-Angiotensin-Aldosterone-System Blocking Drugs in Patients with SARS-CoV-2 - Systematic Review and Meta-Analysis
}

\author{
Chang Chu ${ }^{1}$, Shufei Zeng ${ }^{2}$, Ahmed Hasan ${ }^{3}$, Carl-Friedrich Hocher ${ }^{4}$, Bernard Kraemer ${ }^{5}$, and \\ Berthold Hocher ${ }^{5}$ \\ ${ }^{1}$ Charite Universitatsmedizin Berlin \\ ${ }^{2}$ Charite Medical Faculty Berlin \\ ${ }^{3}$ University of Potsdam \\ ${ }^{4}$ University of Heidelberg \\ ${ }^{5}$ University of Heidelberg, Medical Faculty Mannheim
}

June 9, 2020

\begin{abstract}
Background and Purpose: COVID-19 patients treated with RAAS blockers are among the patients at highest risk of poor outcome. ACE2 is the functional receptor for SARS-CoV-2. Animal studies suggest that RAAS blockers might increase the expression of ACE2 and potentially increase the risk of SARS-Cov-2 infection. Experimental Approach and Key Results: The effect of ACE inhibitor treatment on the incidence of pneumonia in non-COVID-19 patients was analyzed in 25 studies (330,780 patients). ACE inhibitor use was associated with a $27 \%$ reduction of pneumonia risk (OR: 0.73, p $<0.001)$. Pneumonia related death cases in ACE inhibitor treated non-COVID-19 patients were reduced by 27\% (OR: 0.73, p=0.004). ARB treatment was analyzed in 10 studies (275,621 non-COVID-19 patients). The risk of pneumonia was not different between patients who did or did not use ARBs. Pooled results from 16 studies in 22,333 COVID-19 patients showed that COVID-19 related server adverse clinical outcomes (admission to ICU, need for assisted ventilation or death) were reduced by $26 \%$ when using RAAS blocking agents $(\mathrm{OR}=0.74, \mathrm{p}=0.04)$. Pooled results from 10 studies in 11,514 COVID-19 patients showed that RAAS blockede reduces all-cause mortality by $41 \%(\mathrm{OR}=0.59, \mathrm{p}=0.01)$. Conclusion and Implications: Given the weak evidence coming from animal studies and the clear beneficial data of ACE inhibition in non-COVID-19 patients and the promising data in COVID-19 patients, the use of RAAS blocking agents in patients with SARS-CoV-2 infection is justified and should be maintained. Further clinical studies analysing ARBs and ACE inhibitors separately in COVID-19 patients are needed.
\end{abstract}

\section{Introduction}

Patients with cardiovascular and renal diseases are frequently treated with drugs interfering with the ReninAngiotensin-Aldosterone (RAAS) System. The clinical benefit of angiotensin-converting enzyme (ACE) inhibitors and angiotensin II receptor blockers (ARBs) are well established and hence became part of treatment guidelines for these patients worldwide. Angiotensin-converting enzyme 2 (ACE2) is an isoenzyme of angiotensin-converting enzyme 1 (ACE). Both are essential parts of the RAAS, see figure 1. ACE2 is involved in cardiac function, the development of hypertension and diabetes mellitus. Also, ACE2 has been identified as a functional receptor for coronaviruses, including SARS-CoV and SARS-CoV-2. SARS-CoV-2 infection is triggered by the binding of the spike protein of the virus to ACE2. It was suggested that patients with cardiac and renal diseases, hypertension, and diabetes, who are treated with drugs potentially increasing ACE2 expression in the lungs such as ACE inhibitors or angiotensin II receptor blockers are at higher risk for severe COVID-19 infection (Fang, Karakiulakis \& Roth, 2020; Zheng, Ma, Zhang \& Xie, 2020). In the current review, we are summarizing the molecular evidence for this hypothesis (see figure 1 and supplementary 
material: Molecular Background), next we present results of a meta-analysis of studies analyzing the effects of RAAS blocking drugs (ACE inhibitors, ARBs) on the risk and mortality of pneumonia in non-COVID-19 patients and also meta-analysed the 17 so far published studies on this topic in COVID-19 patients.

\section{Methods}

\section{Data sources and search strategy}

A systematic literature search was conducted to identify studies investigating the association between ACE inhibitors or ARBs and pneumonia or COVID-19 in PubMed. The last search was updated on June $6^{\text {th }}$, 2020. The following MeSH terms were used in PubMed: "Angiotensin-Converting Enzyme Inhibitors" or "Angiotensin Receptor Antagonists" or "Mineralocorticoid Receptor Antagonists" and "Pneumonia". Detailed search terms and search strategy are described in the supplementary file. The references cited in the retrieved studies were hand-searched for the collection of missing relevant studies. Details of study selection and quality assessment as well as data extraction and analysis are provided in the supplementary materials.

\section{Result}

\section{Literature search \&description of studies}

We identified 965 potentially relevant studies using the search terms described in the method section. After screening titles and abstracts, a total of 809 publications were excluded. 102 out of the remaining 156 publications were excluded after full-text examination based on our in- and exclusion criteria. Overall, 54 studies were included in our present analysis, including 23 cohort studies (Arai et al., 2005; Arai et al., 2000; Chalmers, Singanayagam, Murray \& Hill, 2008; Feng et al., 2020; Gao et al., 2020; Harada \& Sekizawa, 2006; Huang et al., 2020; Ishifuji et al., 2017; Jung, Choi, You \& Kim, 2020; Li, Wang, Chen, Zhang \& Deng, 2020; Li et al., 2020; Mehra, Desai, Kuy, Henry \& Patel, 2020a; Mehta et al., 2020; Meng et al., 2020; Mortensen et al., 2012; Mortensen et al., 2008; Mortensen, Restrepo, Anzueto \& Pugh, 2005; Myles, Hubbard, Gibson, Pogson, Smith \& McKeever, 2009; Sekizawa, Matsui, Nakagawa, Nakayama \& Sasaki, 1998; Shah et al., 2014; Tan, Qiu, Xing, Ghosh, Chen \& Mao, 2020; Teramoto \& Ouchi, 1999; Yang et al., 2020), 12 randomized controlled trials (1997; Amat-Santos et al., 2020; Dahlof et al., 2002; Hou et al., 2006; Kanda, Ebihara, Yasuda, Takashi, Sasaki \& Sasaki, 2004; Kasanuki et al., 2009; Kober et al., 1995; Lee et al., 2015; Ohkubo et al., 2004; Schrader et al., 2005; Weber, 1997; Widimsky, Kremer, Jerie \& Uhlir, 1995), 14 case-control studies (de Abajo et al., 2020; El Solh, Brewer, Okada, Bashir \& Gough, 2004; Gnavi, Demaria, Picariello, Dalmasso, Ricceri \& Costa, 2020; Henry, Zaizafoun, Stock, Ghamande, Arroliga \& White, 2018; Mancia, Rea, Ludergnani, Apolone \& Corrao, 2020; Marciniak, Korutz, Lin, Roth, Welty \& Lovell, 2009; Myles, Hubbard, McKeever, Pogson, Smith \& Gibson, 2009; Okaishi et al., 1999; Reynolds et al., 2020; Takahashi et al., 2005; van de Garde, Souverein, Hak, Deneer, van den Bosch \& Leufkens, 2007; van de Garde, Souverein, van den Bosch, Deneer \& Leufkens, 2006; Zhang et al., 2020; Zhou et al., 2020), three nested case-control studies (Dublin, Walker, Jackson, Nelson, Weiss \& Jackson, 2012; Etminan, Zhang, Fitzgerald \& Brophy, 2006; Mukamal, Ghimire, Pandey, O'Meara \& Gautam, 2010) and two case-crossover studies (Liu, Shau, Chang, Wu \& Lai, 2013; Liu, Shau, Wu \& Lai, 2012) (Supplementary figure 1).

As for the primary and secondary pneumonia releated outcomes, totally 36 studies were included. All the randomized controlled trials were multicenter, except one done by Hou et al.(Hou et al., 2006) Seven of them compared ACE inhibitors with controls (1997; Hou et al., 2006; Kanda, Ebihara, Yasuda, Takashi, Sasaki \& Sasaki, 2004; Kober et al., 1995; Lee et al., 2015; Ohkubo et al., 2004; Widimsky, Kremer, Jerie \& Uhlir, 1995), four compared ARBs with controls (Dahlof et al., 2002; Kasanuki et al., 2009; Schrader et al., 2005; Weber, 1997). Regarding demographic distribution, two were done worldwide (Ohkubo et al., 2004; Weber, 1997), four in Europe (1997; Kober et al., 1995; Schrader et al., 2005; Widimsky, Kremer, Jerie \& Uhlir, 1995) (Germany, Czech Republic and Slovakia, Austria, Denmark and Italy), four in Asia (Hou et al., 2006; Kanda, Ebihara, Yasuda, Takashi, Sasaki \& Sasaki, 2004; Kasanuki et al., 2009; Lee et al., 2015) (China, Japan), and one study was located in both Europe and the United States (Dahlof et al., 2002). Among observational studies, ten were carried out in Asia,(Arai et al., 2005; Arai et al., 2000; Harada \& Sekizawa, 
2006; Ishifuji et al., 2017; Liu, Shau, Chang, Wu \& Lai, 2013; Liu, Shau, Wu \& Lai, 2012; Okaishi et al., 1999; Sekizawa, Matsui, Nakagawa, Nakayama \& Sasaki, 1998; Takahashi et al., 2005; Teramoto \& Ouchi, 1999) ten in the United States and Canada (Dublin, Walker, Jackson, Nelson, Weiss \& Jackson, 2012; El Solh, Brewer, Okada, Bashir \& Gough, 2004; Etminan, Zhang, Fitzgerald \& Brophy, 2006; Henry, Zaizafoun, Stock, Ghamande, Arroliga \& White, 2018; Marciniak, Korutz, Lin, Roth, Welty \& Lovell, 2009; Mortensen et al., 2012; Mortensen et al., 2008; Mortensen, Restrepo, Anzueto \& Pugh, 2005; Mukamal, Ghimire, Pandey, O'Meara \& Gautam, 2010; Shah et al., 2014), five in Europe (Chalmers, Singanayagam, Murray \& Hill, 2008; Myles, Hubbard, Gibson, Pogson, Smith \& McKeever, 2009; Myles, Hubbard, McKeever, Pogson, Smith \& Gibson, 2009; van de Garde, Souverein, Hak, Deneer, van den Bosch \& Leufkens, 2007; van de Garde, Souverein, van den Bosch, Deneer \& Leufkens, 2006), 18 studies were retrospective and seven were prospective. 20 studies evaluated ACE inhibitors, six ARBs. Supplementary tables 1- 3 summarize the main characteristics of the included studies.

With regard to the COVID-19-infected patients, 18 studies published clinical data whether ACE inhibitors and ARBs are associated with COVID-19 infection or clinical outcomes in patients with COVID-19 in PubMed. One of them was a global study (Mehra, Desai, Kuy, Henry \& Patel, 2020a), however, this study has been retracted at Jun $4^{\text {th }}$ concerning about the quality of the information in the database, thus we only qualitatively summarized this study. Ten of them were conducted in China (Feng et al., 2020; Gao et al., 2020; Huang et al., 2020; Li, Wang, Chen, Zhang \& Deng, 2020; Li et al., 2020; Meng et al., 2020; Tan, Qiu, Xing, Ghosh, Chen \& Mao, 2020; Yang et al., 2020; Zhang et al., 2020; Zhou et al., 2020), two in the USA(Mehta et al., 2020; Reynolds et al., 2020), two in Italy (Gnavi, Demaria, Picariello, Dalmasso, Ricceri \& Costa, 2020; Mancia, Rea, Ludergnani, Apolone \& Corrao, 2020), two in Spain (Amat-Santos et al., 2020; de Abajo et al., 2020) and one in Korea(Jung, Choi, You \& Kim, 2020). The included studies consist of 12 cohort studies (Feng et al., 2020; Gao et al., 2020; Huang et al., 2020; Jung, Choi, You \& Kim, 2020; Li, Wang, Chen, Zhang \& Deng, 2020; Li et al., 2020; Mehra, Desai, Kuy, Henry \& Patel, 2020a; Mehta et al., 2020; Meng et al., 2020; Tan, Qiu, Xing, Ghosh, Chen \& Mao, 2020; Yang et al., 2020; Zhou et al., 2020), five case-control studies (de Abajo et al., 2020; Gnavi, Demaria, Picariello, Dalmasso, Ricceri \& Costa, 2020; Mancia, Rea, Ludergnani, Apolone \& Corrao, 2020; Reynolds et al., 2020; Zhang et al., 2020) and one randomized controlled trials (Amat-Santos et al., 2020) (Supplementary table 4).

\section{Primary outcomes:incidence of pneumonia}

The effect of ACE inhibitor treatment on the incidence of pneumonia was analyzed in 25 studies (a total of 330,780 patients coming from five randomized controlled trials (1997; Kober et al., 1995; Lee et al., 2015; Ohkubo et al., 2004; Widimsky, Kremer, Jerie \& Uhlir, 1995), seven cohort studies (Arai et al., 2005; Arai et al., 2000; Harada \& Sekizawa, 2006; Ishifuji et al., 2017; Sekizawa, Matsui, Nakagawa, Nakayama \& Sasaki, 1998; Shah et al., 2014; Teramoto \& Ouchi, 1999), eight case-control studies (El Solh, Brewer, Okada, Bashir \& Gough, 2004; Henry, Zaizafoun, Stock, Ghamande, Arroliga \& White, 2018; Marciniak, Korutz, Lin, Roth, Welty \& Lovell, 2009; Myles, Hubbard, McKeever, Pogson, Smith \& Gibson, 2009; Okaishi et al., 1999; Takahashi et al., 2005; van de Garde, Souverein, Hak, Deneer, van den Bosch \& Leufkens, 2007; van de Garde, Souverein, van den Bosch, Deneer \& Leufkens, 2006), three nested case-control studies (Dublin, Walker, Jackson, Nelson, Weiss \& Jackson, 2012; Etminan, Zhang, Fitzgerald \& Brophy, 2006; Mukamal, Ghimire, Pandey, O'Meara \& Gautam, 2010) and two case-crossover studies(Liu, Shau, Chang, Wu \& Lai, 2013; Liu, Shau, Wu \& Lai, 2012)). Overall, the use of ACE inhibitors was associated with a significant $27 \%$ reduction in risk of pneumonia compared with controls (pooled OR, 0.73; 95\% CI, 0.64 to 0.83; p<0.001; $\mathrm{I}^{2}=78.5 \%$ ), for further details see Figure 2 .

The effect of ARB treatment on the incidence of pneumonia was analyzed in 10 studies (a total of 275,621 patients coming from four randomized controlled trials, (Dahlof et al., 2002; Kasanuki et al., 2009; Schrader et al., 2005; Weber, 1997) one cohort study (Shah et al., 2014), one case-control study (Henry, Zaizafoun, Stock, Ghamande, Arroliga \& White, 2018), two nested case-control studies (Etminan, Zhang, Fitzgerald \& Brophy, 2006; Mukamal, Ghimire, Pandey, O’Meara \& Gautam, 2010) and two case-crossover studies (Liu, Shau, Chang, Wu \& Lai, 2013; Liu, Shau, Wu \& Lai, 2012). 
Pooled results showed that the risk of pneumonia was not significantly different between patients who did or did not use ARBs (pooled OR, 0.90; 95\% CI, 0.79 to $1.02 ; \mathrm{p}=0.11 ; \mathrm{I}^{2}=53.3 \%$ ).

However, two individual study types revealed a potential effect of ARBs on the risk of pneumonia. The odds ratios were $0.84\left(95 \% \mathrm{CI}, 0.72\right.$ to $\left.0.98 ; \mathrm{p}=0.03 ; \mathrm{I}^{2}=0 \%\right)$ in randomized controlled trials and $0.52(95 \% \mathrm{CI}$, 0.36 to $0.76, \mathrm{p}=0.001$ ) in the cohort study, respectively (Figure 3 ).

\section{Secondary outcome: pneumonia-related mortality}

Data of pneumonia-related deaths were available in 10 studies, one of which was comparing ARBs with control summarized qualitatively (Mortensen et al., 2012), nine studies comparing ACE inhibitors with controls (four randomized controlled trials (Hou et al., 2006; Kanda, Ebihara, Yasuda, Takashi, Sasaki \& Sasaki, 2004; Lee et al., 2015; Ohkubo et al., 2004), and five cohort studies (Chalmers, Singanayagam, Murray \& Hill, 2008; Mortensen et al., 2012; Mortensen, Restrepo, Anzueto \& Pugh, 2005; Mortensen, Restrepo, Copeland, Pugh \& Anzueto, 2008; Myles, Hubbard, Gibson, Pogson, Smith \& McKeever, 2009) were included in the meta-analysis.

Pooled results showed that ACE inhibitors were associated with a significant $27 \%$ reduction in risk of pneumonia-related mortality (OR, $0.73 ; 95 \%$ CI, 0.59 to $0.90 ; \mathrm{p}=0.004 ; \mathrm{I}^{2}=60.1 \%$ ) compared with controls (Figure 4).

For ARBs, a meta-analysis for the secondary end-point mortality was not possible due to the lack of enough eligible studies. Mortensen et al. (Mortensen et al., 2012), conducted the only eligible study providing data on ARB and pneumonia related mortality. They showed in a cohort of 22,996 patients where 839 subjects were treated with ARBs that treatment with ARBs reduced the pneumonia-related mortality (OR, 0.47; $95 \%$ CI, 0.30 to 0.72 ).

\section{Mineralocorticoid Receptor Antagonists}

We did not find any eligible studies addressing the effects of mineralocorticoid receptor antagonists on pneumonia or pneumonia related death.

\section{Renin-angiotensin system inhibitors and risk of COVID-19}

Pooled result from 16 studies (Amat-Santos et al., 2020; de Abajo et al., 2020; Feng et al., 2020; Gao et al., 2020; Huang et al., 2020; Jung, Choi, You \& Kim, 2020; Li, Wang, Chen, Zhang \& Deng, 2020; Li et al., 2020; Mancia, Rea, Ludergnani, Apolone \& Corrao, 2020; Mehta et al., 2020; Meng et al., 2020; Reynolds et al., 2020; Tan, Qiu, Xing, Ghosh, Chen \& Mao, 2020; Yang et al., 2020; Zhang et al., 2020; Zhou et al., 2020), a total of 22,333 patients, showed that the risk of COVID-19 related severe adverse clinical outcomes (admission to the intensive care unit, the use of assisted ventilation, or death) was significant reduced in patients who use ACE inhibitors/ARBs (0.74, 0.56 to 0.99; $\mathrm{p}=0.04 ; \mathrm{I}^{2}=78.5 \%$ ) (Figure 5). Unfortunately, few studies allow a differentiation analysis of ACE inhibitors and ARBs treatment separately. Both ACE inhibitors $\left(0.93,0.76\right.$ to $\left.1.13 ; \mathrm{p}=0.45 ; \mathrm{I}^{2}=60.6 \%\right)$ and $\mathrm{ARB}\left(0.96,0.76\right.$ to $\left.1.22 ; \mathrm{p}=0.75 ; \mathrm{I}^{2}=46.9 \%\right)$ point to the right direction. However, these associations were not significant.

Furthermore, ten studies (Gao et al., 2020; Huang et al., 2020; Jung, Choi, You \& Kim, 2020; Li, Wang, Chen, Zhang \& Deng, 2020; Mehta et al., 2020; Meng et al., 2020; Tan, Qiu, Xing, Ghosh, Chen \& Mao, 2020; Yang et al., 2020; Zhang et al., 2020; Zhou et al., 2020) including 11,514 patients showed that the risk of allcause mortality among ACE inhibitors/ARBs users was significantly reduced when compared to COVID-19 patients without $\mathrm{ACE}$ inhibitors/ARBs treatment (odds ratio 0.59, 0.39 to $0.90 ; \mathrm{p}=0.01 ; \mathrm{I}^{2}=55.1 \%$ ) (Figure 6). Pooled result from four studies, five cohorts (62,243 patients) (Gnavi, Demaria, Picariello, Dalmasso, Ricceri \& Costa, 2020; Mancia, Rea, Ludergnani, Apolone \& Corrao, 2020; Mehta et al., 2020; Reynolds et al., 2020) showed that the risk of getting infected (whatever degree of disease - from no symptoms to severe adverse clinical outcomes) was not associated with the treatment of ACE inhibitors/ARBs (1.01, 0.85 to $1.20 ; \mathrm{p}=0.91 ; \mathrm{I}^{2}=84.7 \%$ ).

\section{Publication bias}


For the primary outcome referring to ACE inhibitors, funnel plot did not show apparent visual asymmetry (Supplementary figure 2). The Begg tests showed no evidence of publication bias $(\mathrm{P}=0.66)$. As for the primary outcome referring to ARBs, funnel plots did not show any asymmetrical tail (Supplementary figure $3)$. Likewise, Begg tests showed no evidence of publication bias $(\mathrm{P}=0.21)$. For the secondary outcome, funnel plot did not show visual asymmetry (Supplementary figure 4).; testing for publication bias showed similar results (Begg's P-value for asymmetry 1.00). As for the COVID-16 studies referring to primary outcome, Begg's test for asymmetry was also not significant $(\mathrm{P}=0.08)$.

\section{Discussion}

Patients treated with RAAS blocking drugs due to cardiac and renal diseases certainly belong to the patients with the highest risk for SARS Cov-2 related non-fatal and fatal pneumonia. RAAS blocking drugs belong to drug classes with the clearest proven clinical benefit to patients with cardiac and renal diseases. Given that ACE2 is the receptor for the SARS Cov-2 virus mediating entry to human cells, drugs that might affect the expression of ACE2 in humans and hence potentially disease severity are of major concern. The definitive answer whether RAAS blocking drugs are beneficial, neutral or even harmful can only come from adequately powered clinical trials that are currently initiated (NCT04311177 (Losartan for Patients With COVID-19 Not Requiring Hospitalization) and NCT04312009 (Losartan for Patients With COVID-19 Requiring Hospitalization). This will take some time. Moreover, our data (see Figures 2 and 3) would rather suggest to study ACE inhibitors instead of ARBs in patients with SARS Cov-2 infecion. In any case, general practitioners and physicians in hospitals, especially on intensive care units, treating patients with SARS $\mathrm{CoV}-2$ infection ask for guidance now. As is often the case in everyday clinical medicine, one has to critically summarize and weigh the existing facts and then make clinical decisions. This is, therefore, the ultimate goal of our investigation and below the key points for decision making are summarized:

1. There is currently no doubt among scientists that ACE2 is the functional receptor of SARS-CoV mediated upper and lower respiratory tract infections (Vaduganathan, Vardeny, Michel, McMurray, Pfeffer \& Solomon, 2020).

2. Wrapp et al.(Wrapp et al., 2020) showed that the COVID-19 S protein binds ACE2 with a much higher affinity than SARS-CoV-2. This could partly explain the high infection rate of this virus.

3. Some animal studies do suggest that treatment with either ACE inhibitors or ARBs might increase ACE2 expression in the cardiovascular system. Few animal data exist on the pulmonary expression of ACE2 under RAAS blockade. It should also be emphasized that some animal studies found no effect or even an opposite effect on ACE2 expression (Burchill, Velkoska, Dean, Griggs, Patel \& Burrell, 2012; Burrell et al., 2005; Ferrario et al., 2005; Ishiyama, Gallagher, Averill, Tallant, Brosnihan \& Ferrario, 2004; Li, Zeng, Huang, Zhou, Zhang \& Jiang, 2015; Ocaranza et al., 2006). It is worth mentioning that one of these studies showed beneficial effects of ACE inhibition although pulmonary ACE2 expression increased (Li, Zeng, Huang, Zhou, Zhang \& Jiang, 2015), for more details see supplementary file Molecular Background.

4. The human heart and kidney expresses ACE2, the receptor for SARS-CoV-2. Several independent studies reported that the heart and potentially the kidney seems to be - besides the respiratory tract - likewise a primary target of SARS-CoV-2 infections leading to clinical signs of myocarditis and heart failure (Chen, Li, Chen, Feng \& Xiong, 2020; Chen et al., 2020; Han et al., 2020; Madjid, SafaviNaeini, Solomon \& Vardeny, 2020) and potentially renal failure (Goicoechea et al., 2020; Noris, Benigni \& Remuzzi, 2020). The RAAS is activated in heart failure patients and RAAS blockade is one of the clinical mainstays in the treatment of heart failure (Bayes-Genis, 2017; de Frutos et al., 2020; Solomon et al., 2017).

5. Our meta-analysis of studies in non-COVID-19 patients clearly indicated that patients treated with ACE inhibitors do have a lower risk of acquiring non-fatal and fatal pneumonia regardless of the underlying cause of pneumonia. The meta-analysis of studies investigating the effects of ARBs, however, showed no clear beneficial effect. In the subset of studies with the highest evidence level (randomized placebo controlled studies) ARBs did, however, reduce the incidence of pneumonia.

6. Our meta-analysis in COVID-19 patients showed that the COVID-19 related severe adverse clinical 
outcomes (admission to the intensive care unit, the use of assisted ventilation, or death) were reduced by $26 \%$ in patients treated with RAAS blocking agents. The risk of all-cause mortality (Figure 6) was even $41 \%$ lower in COVID-19 patients using RAAS blocking drugs.

Our findings in COVID-19 infected patients with regard to RAAS blocking agents are thus in good agreement with findings in non-COVID-19-infected patients with pneumonias. The smaller numbers of analysed COVID-19 positive patients and the study design of these studies do not allow a differentiation of ACE inhibitors and ARBs effects with regard to severe adverse clinical outcomes and all cause mortality. The findings in COVID-19 patients are for sure less robust compared to the non-CORVID-19 studies. This is simply due to the by far lower number of analysed COVID-19 patients so far.

Based on the data in non-COVID-19 and COVID-19 patients, we strongly suggest that in particular ACE inhibitors should not be discontinued in patients who need them due to cardiac and/or renal diseases. The evidence that ACE inhibitors might affect the expression of the molecular target in humans for the SARS $\mathrm{CoV}-2$ virus (ACE2) is controversial and comes from animal experiments. Moreover, the potential implication of an up- or down-regulation (except for ACE2 knockout mice) of ACE2 on the risk of infection of the lungs with SARS CoV-2 is not established so far.

The meta-analysis of all available clinical studies in non-COVID-19 patients provides clearcut results. ACE inhibitors are beneficial for patients with pneumonia. They reduce the odds for pneumonia and also pneumonia related death. The limited experience so far in COVID-19 patients clearly supports this interpretation.

For ARBs the situation is less clear. The overall effect in non-COVID-19 pneumonia outcomes were neutral (Figure 3). The data in COVID-19 patients are clear: RAAS blockade - whatever drug class was used - reduces severe adverse clinical outcomes and all-cause mortality. We do not know for the time being wheather ACE inhibitors or ARBs or both compound classes were the drivers of these beneficial effects. Final conclusions can only be made when we have enough studies on this topic separating the effects of ACE inhibiors from ARBs in COVID-19 patients.

To ensure the quality of our study, we just accepted studies in international jounals after sussesful peer review, pre-prints were not considered. We excluded even one COVID-19 study published in the NEJM (Mehra, Desai, Kuy, Henry \& Patel, 2020a), because the quality of the data was questioned after publication even by the senior editor of this journal (Mehra, Desai, Kuy, Henry \& Patel, 2020b; Rubin, 2020).

It represents a study limitation that the vast majority of analysed cases of pneumonia in our meta-analysis had not been caused by SARS-CoV-2 infections. The somewhat high heterogeneity in our analysis - in particular in the COVID-19 studies - is due to differences in the design of the individual studies, different population analysed and the way of statistical analysis of the original studies. Moreover, there was some heterogeneity regarding the controls used in the meta-analysis due to the definition of control group (the control group was defined as being treated with a placebo or any other cardiovascular drug such as calcium channel blocker or beta-blockers) used in our study. In addition, the secondary outcome of the meta-analysis in non-COVID-19 patients was defined as pneumonia-related mortality. We accepted the following definitions in the individual studies as pneumonia related mortality: fatal pneumonia or in-hospital death or 30-day mortality in patients with pneumonia. For the COVID- 19, outcome severe adverse clinical events, we accepted admission to the intensive care unit, the use of assisted ventilation, or death or combinations as severe adverse clinical event. These differences due to the particular outcome definitions in the individual studies may likewise increase heterogeneity. Moreover was the baseline morbitity and mortality risk of the patients different in the individual studies furthermore increasing heterogeneity. Finally, we had no informations on the dosages of the used RASS blocking agents - so any analysis of dose-dependency of the observed effects was not possible.

An investigation of this topic in a meta-analysis of all so far available studies in non-SARS-CoV-2 pneumonia combined with an analysis of the available studies in COVID-19 patients is the as of today best available approach to obtain clinical evidence on this extremely important clinical question unless adequately powered, placebo-controlelled studies adressing this topic as primary outcome in COVID-19 patients are available. 
Furthermore, it is justified to assume that factors that determine the progression, severity and course of pneumonia in general are factors that also determine the course of SARS-Cov-2 pneumonia (Hendrickson \& Matthay, 2013; Mizgerd, 2017; Tsukagoshi, Ishioka, Noda, Kozawa \& Kimura, 2013). This hypothesis is supported by findings of pathological lung alterations in early disease stages of SARS-CoV-2 infection. Early histopathological features were non-specific and included oedema, pneumocyte hyperplasia, focal inflammation and multinucleated giant cell formation; findings also seen in early stages of non-SARS-Cov-2 pneumonias (Tian, Hu, Niu, Liu, Xu \& Xiao, 2020). Figure 1 illustrates the basic science and clinical points discussed above.

In conclusion, considering the overall very weak evidence in animal studies that the RAAS blockade related alterations of the pulmonary ACE2 expression is linked to disease severity and the clear beneficial data of ACE inhibition in non-COVID patients on the incidence of pneumonia and pneumonia related death, the use of ACE inhibitors in SARS-CoV-2 infected patients who need these drugs due to their cardiac and renal diseases is justified and these compounds should not be withdrawn. Our findings provide a stimulus for the initiation of randomized clinical trials investigating ACE inhibitors in SARS-CoV-2 patients. The results with regard to ARBs, however, are less clearcut. Its use is safe and the finding that RAAS blockade (ACE inhibition and ARBs treatment was unfortunately analysed not individually in the currently available studies in the target population) in COVID-19 patients reduces adverse outcomes in general and even allcause mortality (Figure 5 and 6 ) asks immeadiatly for adequately designed outcome studies with ARBs and ACE inhibitors to disect ACE inhibitor effects from ARBs related effects in this population.

Role of the Funding Source: There was no external funding for this study. All authors had full access to all the data in the study and the corresponding author had final responsibility for the decision to submit for publication.

Disclosure Statement: The authors have no conflicts of interest to declare.

Conflict of Interest: there is no conflict of interest for any of the authors.

\section{References}

(1997). Randomised placebo-controlled trial of effect of ramipril on decline in glomerular filtration rate and risk of terminal renal failure in proteinuric, non-diabetic nephropathy. The GISEN Group (Gruppo Italiano di Studi Epidemiologici in Nefrologia). Lancet 349:1857-1863.

Amat-Santos IJ, Santos-Martinez S, Lopez-Otero D, Nombela-Franco L, Gutierrez-Ibanes E, Del Valle R, et al. (2020). Ramipril in High Risk Patients with COVID-19. J Am Coll Cardiol.

Arai T, Sekizawa K, Ohrui T, Fujiwara H, Yoshimi N, Matsuoka H, et al. (2005). ACE inhibitors and protection against pneumonia in elderly patients with stroke. Neurology 64: 573-574.

Arai T, Yasuda Y, Takaya T, Toshima S, Kashiki Y, Yoshimii N, et al. (2000). Angiotensin-converting enzyme inhibitors, angiotensin II receptor antagonists, and symptomless dysphagia. Chest 117:1819-1820.

Bayes-Genis A (2017). Highlights of the 2016 European Society of Cardiology Guidelines on Heart Failure. Eur Cardiol 12: 76-77.

Burchill LJ, Velkoska E, Dean RG, Griggs K, Patel SK, \& Burrell LM (2012). Combination renin-angiotensin system blockade and angiotensin-converting enzyme 2 in experimental myocardial infarction: implications for future therapeutic directions. Clin Sci (Lond) 123: 649-658.

Burrell LM, Risvanis J, Kubota E, Dean RG, MacDonald PS, Lu S, et al. (2005). Myocardial infarction increases ACE2 expression in rat and humans. Eur Heart J 26: 369-375; discussion 322-364.

Chalmers JD, Singanayagam A, Murray MP, \& Hill AT (2008). Prior statin use is associated with improved outcomes in community-acquired pneumonia. Am J Med 121: 1002-1007 e1001. 
Chen L, Li X, Chen M, Feng Y, \& Xiong C (2020). The ACE2 expression in human heart indicates new potential mechanism of heart injury among patients infected with SARS-CoV-2. Cardiovasc Res.

Chen T, Wu D, Chen H, Yan W, Yang D, Chen G, et al. (2020). Clinical characteristics of 113 deceased patients with coronavirus disease 2019: retrospective study. BMJ 368: m1091.

Dahlof B, Devereux RB, Kjeldsen SE, Julius S, Beevers G, de Faire U, et al. (2002). Cardiovascular morbidity and mortality in the Losartan Intervention For Endpoint reduction in hypertension study (LIFE): a randomised trial against atenolol. Lancet 359:995-1003.

de Abajo FJ, Rodriguez-Martin S, Lerma V, Mejia-Abril G, Aguilar M, Garcia-Luque A, et al. (2020). Use of renin-angiotensin-aldosterone system inhibitors and risk of COVID-19 requiring admission to hospital: a case-population study. Lancet.

de Frutos F, Mirabet S, Ortega-Paz L, Buera I, Darnes S, Farre N, et al. (2020). Management of Heart Failure with Reduced Ejection Fraction after ESC 2016 Heart Failure Guidelines: The Linx Registry. ESC Heart Fail 7: 25-35.

Dublin S, Walker RL, Jackson ML, Nelson JC, Weiss NS, \& Jackson LA (2012). Angiotensin-converting enzyme inhibitor use and pneumonia risk in community-dwelling older adults: results from a populationbased case-control study. Pharmacoepidemiol Drug Saf 21: 1173-1182.

El Solh AA, Brewer T, Okada M, Bashir O, \& Gough M (2004). Indicators of recurrent hospitalization for pneumonia in the elderly. Journal of the American Geriatrics Society 52: 2010-2015.

Etminan M, Zhang B, Fitzgerald M, \& Brophy JM (2006). Do angiotensin-converting enzyme inhibitors or angiotensin II receptor blockers decrease the risk of hospitalization secondary to community-acquired pneumonia? A nested case-control study. Pharmacotherapy 26: 479-482.

Fang L, Karakiulakis G, \& Roth M (2020). Are patients with hypertension and diabetes mellitus at increased risk for COVID-19 infection? Lancet Respir Med.

Feng Y, Ling Y, Bai T, Xie Y, Huang J, Li J, et al. (2020). COVID-19 with Different Severity: A Multi-center Study of Clinical Features. American journal of respiratory and critical care medicine.

Ferrario CM, Jessup J, Chappell MC, Averill DB, Brosnihan KB, Tallant EA, et al. (2005). Effect of angiotensin-converting enzyme inhibition and angiotensin II receptor blockers on cardiac angiotensinconverting enzyme 2. Circulation 111: 2605-2610.

Gao C, Cai Y, Zhang K, Zhou L, Zhang Y, Zhang X, et al. (2020). Association of hypertension and antihypertensive treatment with COVID-19 mortality: a retrospective observational study. Eur Heart J.

Gnavi R, Demaria M, Picariello R, Dalmasso M, Ricceri F, \& Costa G (2020). Therapy with agents acting on the renin-angiotensin system and risk of SARS-CoV-2 infection. Clin Infect Dis.

Goicoechea M, Sanchez Camara LA, Macias N, Munoz de Morales A, Gonzalez Rojas A, Bascunana A, et al. (2020). COVID-19: Clinical course and outcomes of 36 maintenance hemodialysis patients from a single center in Spain. Kidney Int.

Han H, Xie L, Liu R, Yang J, Liu F, Wu K, et al. (2020). Analysis of heart injury laboratory parameters in 273 COVID-19 patients in one hospital in Wuhan, China. J Med Virol.

Harada J, \& Sekizawa K (2006). Angiotensin-converting enzyme inhibitors and pneumonia in elderly patients with intracerebral hemorrhage. Journal of the American Geriatrics Society 54: 175-176.

Hendrickson CM, \& Matthay MA (2013). Viral pathogens and acute lung injury: investigations inspired by the SARS epidemic and the 2009 H1N1 influenza pandemic. Semin Respir Crit Care Med 34: 475-486.

Henry C, Zaizafoun M, Stock E, Ghamande S, Arroliga AC, \& White HD (2018). Impact of angiotensinconverting enzyme inhibitors and statins on viral pneumonia. Proc (Bayl Univ Med Cent) 31: 419-423. 
Hou FF, Zhang X, Zhang GH, Xie D, Chen PY, Zhang WR, et al.(2006). Efficacy and safety of benazepril for advanced chronic renal insufficiency. N Engl J Med 354: 131-140.

Huang Z, Cao J, Yao Y, Jin X, Luo Z, Xue Y, et al. (2020). The effect of RAS blockers on the clinical characteristics of COVID-19 patients with hypertension. Ann Transl Med 8: 430.

Ishifuji T, Sando E, Kaneko N, Suzuki M, Kilgore PE, Ariyoshi K, et al. (2017). Recurrent pneumonia among Japanese adults: disease burden and risk factors. BMC Pulm Med 17: 12.

Ishiyama Y, Gallagher PE, Averill DB, Tallant EA, Brosnihan KB, \& Ferrario CM (2004). Upregulation of angiotensin-converting enzyme 2 after myocardial infarction by blockade of angiotensin II receptors. Hypertension 43: 970-976.

Jung SY, Choi JC, You SH, \& Kim WY (2020). Association of renin-angiotensin-aldosterone system inhibitors with COVID-19-related outcomes in Korea: a nationwide population-based cohort study. Clin Infect Dis.

Kanda A, Ebihara S, Yasuda H, Takashi O, Sasaki T, \& Sasaki H (2004). A combinatorial therapy for pneumonia in elderly people. Journal of the American Geriatrics Society 52: 846-847.

Kasanuki H, Hagiwara N, Hosoda S, Sumiyoshi T, Honda T, Haze K, et al. (2009). Angiotensin II receptor blocker-based vs. non-angiotensin II receptor blocker-based therapy in patients with angiographically documented coronary artery disease and hypertension: the Heart Institute of Japan Candesartan Randomized Trial for Evaluation in Coronary Artery Disease (HIJ-CREATE). Eur Heart J 30: 1203-1212.

Kober L, Torp-Pedersen C, Carlsen JE, Bagger H, Eliasen P, Lyngborg K, et al. (1995). A clinical trial of the angiotensin-converting-enzyme inhibitor trandolapril in patients with left ventricular dysfunction after myocardial infarction. Trandolapril Cardiac Evaluation (TRACE) Study Group. N Engl J Med 333:16701676.

Lee JS, Chui PY, Ma HM, Auyeung TW, Kng C, Law T, et al. (2015). Does Low Dose Angiotensin Converting Enzyme Inhibitor Prevent Pneumonia in Older People With Neurologic Dysphagia-A Randomized Placebo-Controlled Trial. Journal of the American Medical Directors Association 16: 702-707.

Li J, Wang X, Chen J, Zhang H, \& Deng A (2020). Association of Renin-Angiotensin System Inhibitors With Severity or Risk of Death in Patients With Hypertension Hospitalized for Coronavirus Disease 2019 (COVID-19) Infection in Wuhan, China. JAMA Cardiol.

Li X, Xu S, Yu M, Wang K, Tao Y, Zhou Y, et al. (2020). Risk factors for severity and mortality in adult COVID-19 inpatients in Wuhan. J Allergy Clin Immunol.

Li Y, Zeng Z, Huang W, Zhou M, Zhang X, \& Jiang W (2015). Angiotensin-converting enzyme inhibition attenuates lipopolysaccharide-induced lung injury by regulating the balance between angiotensin-converting enzyme and angiotensin-converting enzyme 2 and inhibiting mitogen-activated protein kinase activation. Shock 43: 395-404.

Liu CL, Shau WY, Chang CH, Wu CS, \& Lai MS (2013). Pneumonia risk and use of angiotensin-converting enzyme inhibitors and angiotensin II receptor blockers. J Epidemiol 23: 344-350.

Liu CL, Shau WY, Wu CS, \& Lai MS (2012). Angiotensin-converting enzyme inhibitor/angiotensin II receptor blockers and pneumonia risk among stroke patients. J Hypertens 30: 2223-2229.

Madjid M, Safavi-Naeini P, Solomon SD, \& Vardeny O (2020). Potential Effects of Coronaviruses on the Cardiovascular System: A Review. JAMA Cardiol.

Mancia G, Rea F, Ludergnani M, Apolone G, \& Corrao G (2020). Renin-Angiotensin-Aldosterone System Blockers and the Risk of Covid-19. N Engl J Med. 
Marciniak C, Korutz AW, Lin E, Roth E, Welty L, \& Lovell L (2009). Examination of selected clinical factors and medication use as risk factors for pneumonia during stroke rehabilitation: a case-control study. Am J Phys Med Rehabil 88: 30-38.

Mehra MR, Desai SS, Kuy S, Henry TD, \& Patel AN (2020a). Cardiovascular Disease, Drug Therapy, and Mortality in Covid-19. N Engl J Med.

Mehra MR, Desai SS, Kuy S, Henry TD, \& Patel AN (2020b). Retraction: Cardiovascular Disease, Drug Therapy, and Mortality in Covid-19. N Engl J Med. DOI: 10.1056/NEJMoa2007621. N Engl J Med.

Mehta N, Kalra A, Nowacki AS, Anjewierden S, Han Z, Bhat P, et al. (2020). Association of Use of Angiotensin-Converting Enzyme Inhibitors and Angiotensin II Receptor Blockers With Testing Positive for Coronavirus Disease 2019 (COVID-19). JAMA Cardiol.

Meng J, Xiao G, Zhang J, He X, Ou M, Bi J, et al. (2020). Renin-angiotensin system inhibitors improve the clinical outcomes of COVID-19 patients with hypertension. Emerg Microbes Infect 9:757-760.

Mizgerd JP (2017). Pathogenesis of severe pneumonia: advances and knowledge gaps. Curr Opin Pulm Med 23: 193-197.

Mortensen EM, Nakashima B, Cornell J, Copeland LA, Pugh MJ, Anzueto A, et al. (2012). Populationbased study of statins, angiotensin II receptor blockers, and angiotensin-converting enzyme inhibitors on pneumonia-related outcomes. Clin Infect Dis 55: 1466-1473.

Mortensen EM, Pugh MJ, Copeland LA, Restrepo MI, Cornell JE, Anzueto A, et al. (2008). Impact of statins and angiotensin-converting enzyme inhibitors on mortality of subjects hospitalised with pneumonia. Eur Respir J 31: 611-617.

Mortensen EM, Restrepo MI, Anzueto A, \& Pugh J (2005). The impact of prior outpatient ACE inhibitor use on 30-day mortality for patients hospitalized with community-acquired pneumonia. BMC Pulm Med $5: 12$.

Mortensen EM, Restrepo MI, Copeland LA, Pugh JA, \& Anzueto A (2008). Association of hydrophilic versus lipophilic angiotensin-converting enzyme inhibitor use on pneumonia-related mortality. Am J Med Sci 336: 462-466.

Mukamal KJ, Ghimire S, Pandey R, O'Meara ES, \& Gautam S (2010). Antihypertensive medications and risk of community-acquired pneumonia. J Hypertens 28: 401-405.

Myles PR, Hubbard RB, Gibson JE, Pogson Z, Smith CJ, \& McKeever TM (2009). The impact of statins, ACE inhibitors and gastric acid suppressants on pneumonia mortality in a UK general practice population cohort. Pharmacoepidemiol Drug Saf 18: 697-703.

Myles PR, Hubbard RB, McKeever TM, Pogson Z, Smith CJ, \& Gibson JE (2009). Risk of communityacquired pneumonia and the use of statins, ace inhibitors and gastric acid suppressants: a population-based case-control study. Pharmacoepidemiol Drug Saf 18: 269-275.

Noris M, Benigni A, \& Remuzzi G (2020). The case of Complement activation in COVID-19 multiorgan impact. Kidney Int.

Ocaranza MP, Godoy I, Jalil JE, Varas M, Collantes P, Pinto M, et al. (2006). Enalapril attenuates downregulation of Angiotensin-converting enzyme 2 in the late phase of ventricular dysfunction in myocardial infarcted rat. Hypertension 48:572-578.

Ohkubo T, Chapman N, Neal B, Woodward M, Omae T, Chalmers J, et al. (2004). Effects of an angiotensinconverting enzyme inhibitor-based regimen on pneumonia risk. American journal of respiratory and critical care medicine 169: 1041-1045. 
Okaishi K, Morimoto S, Fukuo K, Niinobu T, Hata S, Onishi T, et al. (1999). Reduction of risk of pneumonia associated with use of angiotensin I converting enzyme inhibitors in elderly inpatients. American journal of hypertension 12: 778-783.

Reynolds HR, Adhikari S, Pulgarin C, Troxel AB, Iturrate E, Johnson SB, et al. (2020). Renin-AngiotensinAldosterone System Inhibitors and Risk of Covid-19. N Engl J Med.

Rubin EJ (2020). Expression of Concern: Mehra MR et al. Cardiovascular Disease, Drug Therapy, and Mortality in Covid-19. N Engl J Med. DOI: 10.1056/NEJMoa2007621. N Engl J Med.

Schrader J, Luders S, Kulschewski A, Hammersen F, Plate K, Berger J, et al. (2005). Morbidity and Mortality After Stroke, Eprosartan Compared with Nitrendipine for Secondary Prevention: principal results of a prospective randomized controlled study (MOSES). Stroke 36: 1218-1226.

Sekizawa K, Matsui T, Nakagawa T, Nakayama K, \& Sasaki H (1998). ACE inhibitors and pneumonia. Lancet 352: 1069.

Shah S, McArthur E, Farag A, Nartey M, Fleet JL, Knoll GA, et al.(2014). Risk of hospitalization for community acquired pneumonia with renin-angiotensin blockade in elderly patients: a population-based study. PLoS One 9: e110165.

Solomon SD, Rizkala AR, Gong J, Wang W, Anand IS, Ge J, et al.(2017). Angiotensin Receptor Neprilysin Inhibition in Heart Failure With Preserved Ejection Fraction: Rationale and Design of the PARAGON-HF Trial. JACC Heart failure 5: 471-482.

Takahashi T, Morimoto S, Okaishi K, Kanda T, Nakahashi T, Okuro M, et al. (2005). Reduction of pneumonia risk by an angiotensin I-converting enzyme inhibitor in elderly Japanese inpatients according to insertion/deletion polymorphism of the angiotensin I-converting enzyme gene. American journal of hypertension 18: 1353-1359.

Tan ND, Qiu Y, Xing XB, Ghosh S, Chen MH, \& Mao R (2020). Associations between Angiotensin Converting Enzyme Inhibitors and Angiotensin II Receptor Blocker Use, Gastrointestinal Symptoms, and Mortality among Patients with COVID-19. Gastroenterology.

Teramoto S, \& Ouchi Y (1999). ACE inhibitors and prevention of aspiration pneumonia in elderly hypertensives. Lancet 353: 843 .

Tian S, Hu W, Niu L, Liu H, Xu H, \& Xiao SY (2020). Pulmonary Pathology of Early-Phase 2019 Novel Coronavirus (COVID-19) Pneumonia in Two Patients With Lung Cancer. J Thorac Oncol.

Tsukagoshi H, Ishioka T, Noda M, Kozawa K, \& Kimura H (2013). Molecular epidemiology of respiratory viruses in virus-induced asthma. Front Microbiol 4: 278.

Vaduganathan M, Vardeny O, Michel T, McMurray JJV, Pfeffer MA, \& Solomon SD (2020). ReninAngiotensin-Aldosterone System Inhibitors in Patients with Covid-19. N Engl J Med.

van de Garde EM, Souverein PC, Hak E, Deneer VH, van den Bosch JM, \& Leufkens HG (2007). Angiotensinconverting enzyme inhibitor use and protection against pneumonia in patients with diabetes. J Hypertens 25: $235-239$.

van de Garde EM, Souverein PC, van den Bosch JM, Deneer VH, \& Leufkens HG (2006). Angiotensinconverting enzyme inhibitor use and pneumonia risk in a general population. Eur Respir J 27: 1217-1222.

Weber M (1997). Clinical safety and tolerability of losartan. Clin Ther 19: 604-616; discussion 603.

Widimsky J, Kremer HJ, Jerie P, \& Uhlir O (1995). Czech and Slovak spirapril intervention study (CASSIS). A randomized, placebo and active-controlled, double-blind multicentre trial in patients with congestive heart failure. Eur J Clin Pharmacol 49: 95-102. 
Wrapp D, Wang N, Corbett KS, Goldsmith JA, Hsieh CL, Abiona O, et al. (2020). Cryo-EM structure of the 2019-nCoV spike in the prefusion conformation. Science 367: 1260-1263.

Yang G, Tan Z, Zhou L, Yang M, Peng L, Liu J, et al. (2020). Effects Of ARBs And ACEIs On Virus Infection, Inflammatory Status And Clinical Outcomes In COVID-19 Patients With Hypertension: A Single Center Retrospective Study. Hypertension.

Zhang P, Zhu L, Cai J, Lei F, Qin JJ, Xie J, et al. (2020). Association of Inpatient Use of Angiotensin Converting Enzyme Inhibitors and Angiotensin II Receptor Blockers with Mortality Among Patients With Hypertension Hospitalized With COVID-19. Circ Res.

Zheng YY, Ma YT, Zhang JY, \& Xie X (2020). COVID-19 and the cardiovascular system. Nat Rev Cardiol.

Zhou F, Liu YM, Xie J, Li H, Lei F, Yang H, et al. (2020). Comparative impacts of angiotensin converting enzyme inhibitors versus angiotensin II receptor blockers on the risk of COVID-19 mortality. Hypertension.

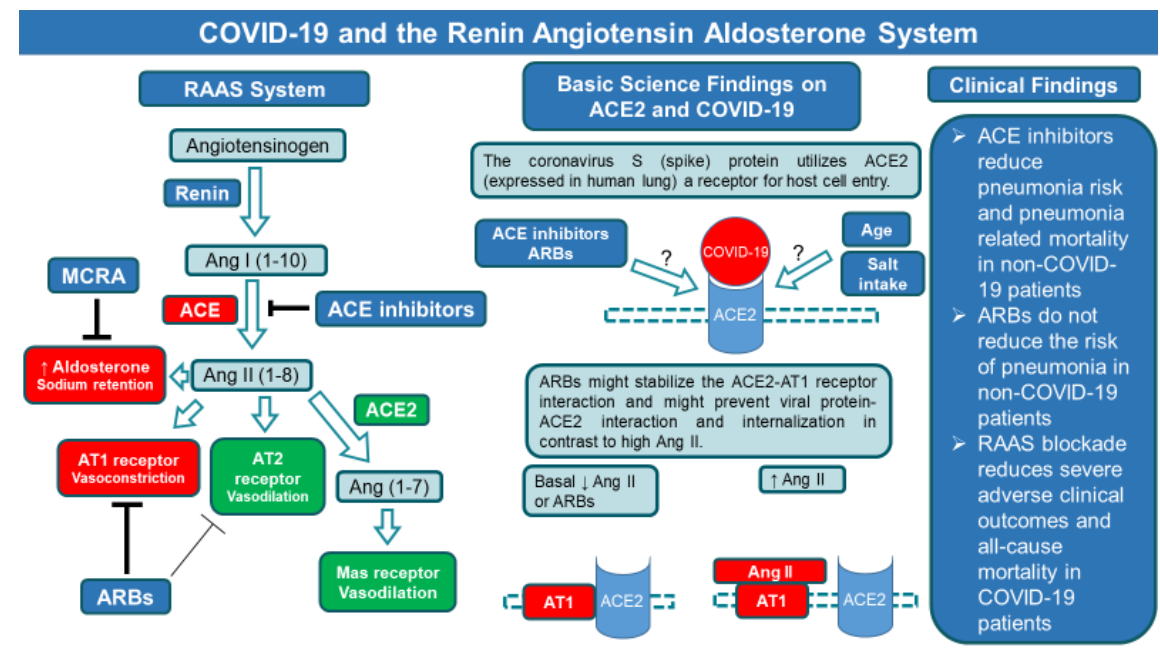

Figure 1. The RAAS controls blood pressure through the systemic secretion of renin from juxtaglomerular cells in the kidneys when renal i.e. blood pressure and/or salt intake are diminished. Renin, then converts angiotensinogen, which is released from the liver, into Ang I (1-10) which is then processed by ACE into Ang II (1-8). This compound stimulates the secretion of aldosterone (mineralocorticoid) from the adrenal cortex leading to sodium retention and acts mainly on AT1 receptors leading to vasoconstriction. ACE2 negatively regulates the RAAS by converting Ang II (1-8) into Ang (1-7) which acts on Mas receptors leading to vasodilation. ACE inhibitors, ARBs and MCRA are widely used as anti-hypertensive drugs and for treatment of heart and renal failure. ACE2 is expressed in human lungs and COVID-19 spike (S) protein seems to use it as a cellular entry receptor. It is still a research question whether age and the use of ACE inhibitors and/or ARBs could impact on ACE2 expression and consequently affect the infection pattern of COVID-19. Another aspect is that ARBs might stabilize the ACE2-AT1 receptor interaction and might prevent viral S protein-ACE2 interaction and internalization, see also supplementary material: Molecular Background. Clinical data indicated that SARS-CoV-2 infection related myocarditis and heart failure may negatively influence outcome of SARS- CoV-2 pneumonia. ACE inhibitor treatment reduces the risk of pneumonia and

pneumonia related mortality, whereas ARBs do not reduce the risk of pneumonia in non-COVID-19 patients. Treatment with RASS blocking drugs reduces severe adverse clinical outcomes and all-cause mortality in COVID-19 patients.

RAAS = Renin angiotensin aldosterone system, $\mathrm{Ang}=$ Angiotensin, $\mathrm{ACE}=$ Angiotensin converting enzyme, 
AT1 receptors $=$ Angiotensin 1 receptors, $\mathrm{ARBs}=$ Angiotensin receptor blockers, MCRA = Mineralocorticoid receptor antagonists, COVID-19 = Coronavirus disease 19.

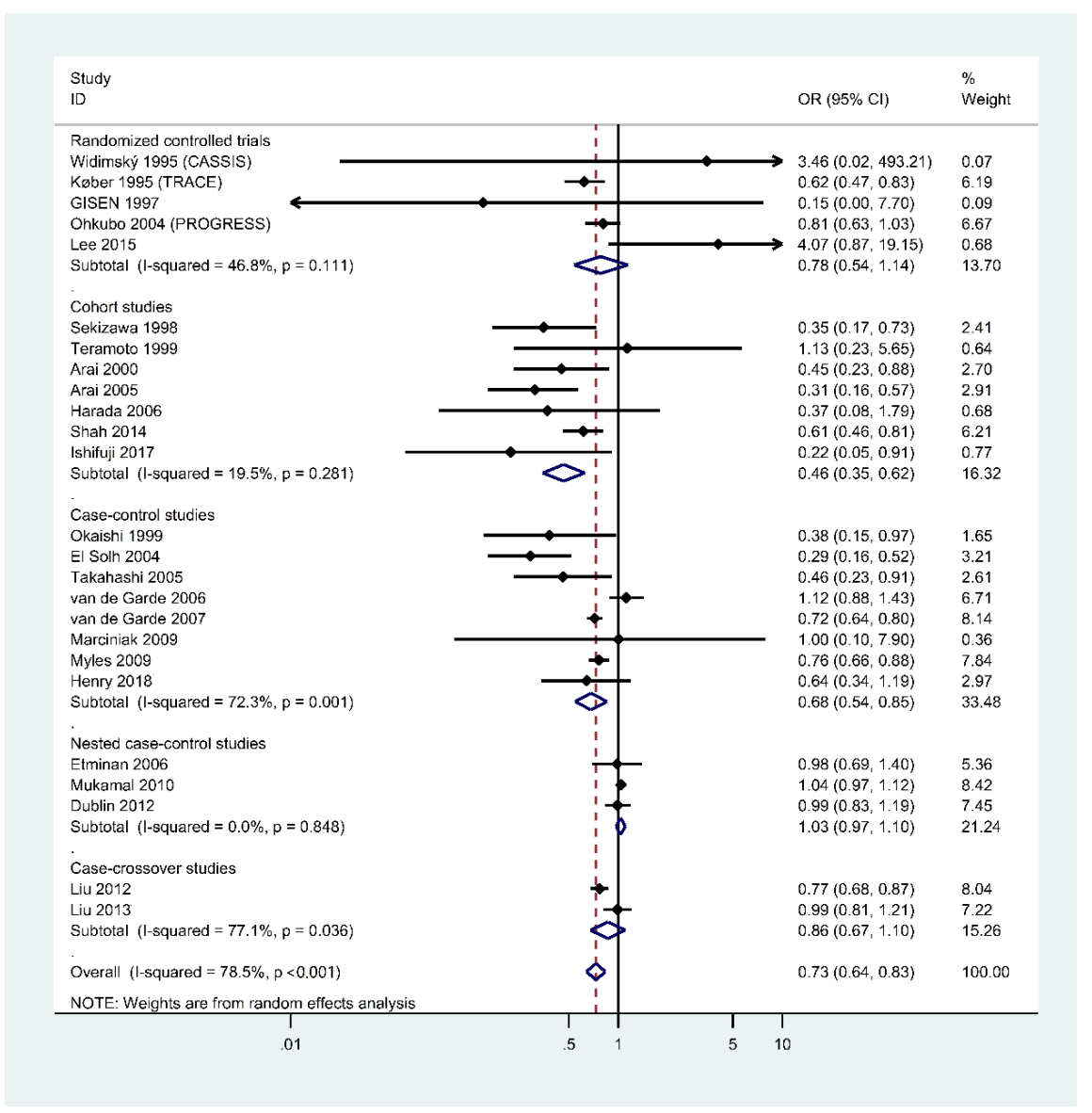

Figure 2 Meta-analysis of the use of angiotensin converting enzyme (ACE) inhibitors on pneumonia risk. The use of ACE inhibitors was associated with a significant $27 \%$ reduction of pneumonia risk compared with controls (OR: $0.73,95 \%$ CI: 0.64 to $0.83 ; \mathrm{p}<0.001$ ). 


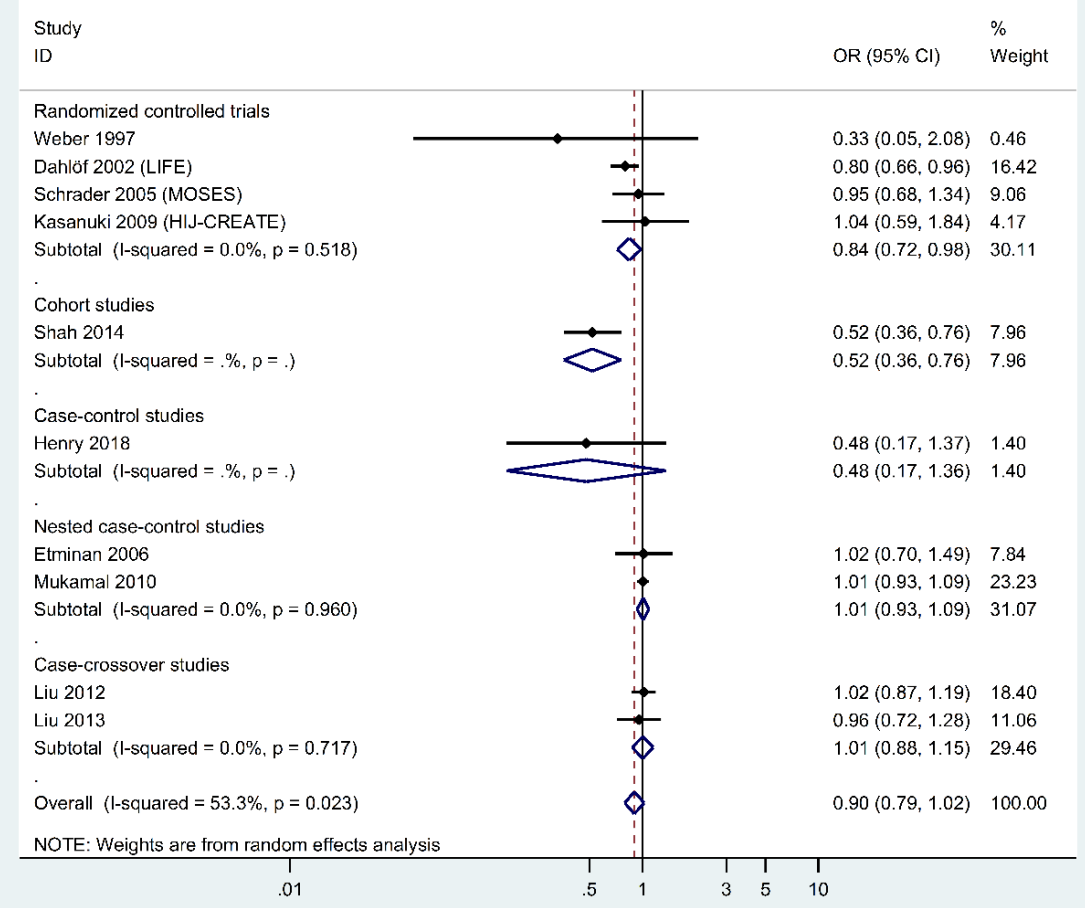

Figure 3. Meta-analysis of the use of angiotensin receptor blockers (ARBs) on pneumonia risk. The risk of pneumonia was not significantly different between patients who did or did not use ARBs (OR, 0.90; $95 \%$ CI, 0.79 to $1.02 ; \mathrm{p}=0.11)$.

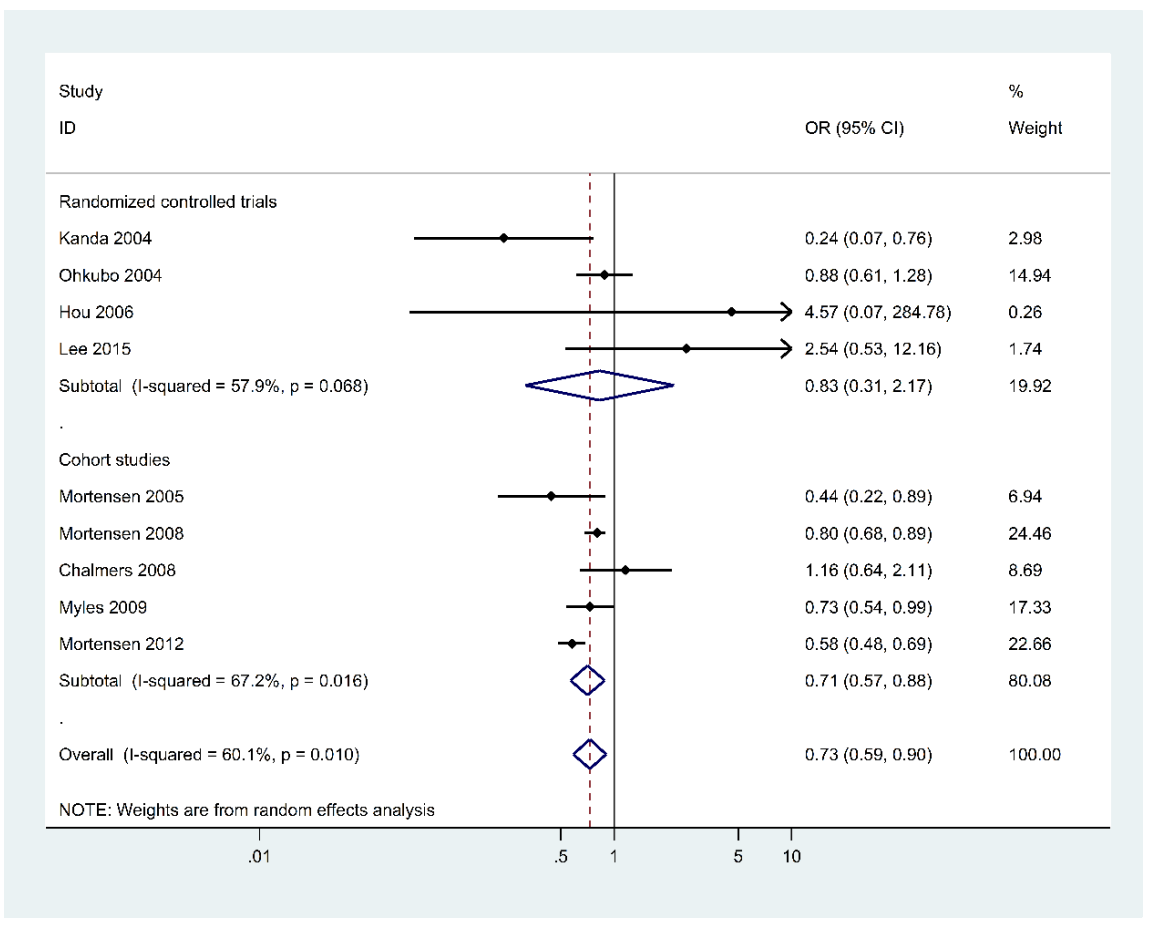


Figure 4. Meta-analysis of the use of angiotensin converting enzyme (ACE) inhibitors on the risk of pneumonia related mortality. Pneumonia related mortality was reduced by $27 \%$ (OR: $0.73 ; 95 \%$ CI, 0.59 to $0.90 ; \mathrm{p}=0.004)$ in patients using angiotensin converting enzyme (ACE) inhibitors.

\section{Hosted file}

image5.emf available at https://authorea.com/users/331359/articles/458049-renin-angiotensinaldosterone-system-blocking-drugs-in-patients-with-sars-cov-2-systematic-review-andmeta-analysis

Figure 5. Meta-analysis of the use of ACE inhibitors/ARBs on the risk of COVID-19 related severe adverse clinical outcomes defined as admission to the intensive care unit (ICU), the use of assisted ventilation, or death $\left(-26 \%\right.$,pooled $\mathrm{OR}=0.74,0.56$ to $\left.0.99 ; \mathrm{p}=0.04 ; \mathrm{I}^{2}=78.5 \%\right)$.

\section{Hosted file}

image6.emf available at https://authorea.com/users/331359/articles/458049-renin-angiotensinaldosterone-system-blocking-drugs-in-patients-with-sars-cov-2-systematic-review-andmeta-analysis

Figure 6. Meta-analysis of the use of ACE inhibitors/ARBs on the risk of all-cause mortality in COVID-19 patients $\left(-41 \%\right.$,pooled $\mathrm{OR}=0.59,0.39$ to $\left.0.90 ; \mathrm{p}=0.01 ; \mathrm{I}^{2}=55.1 \%\right)$. 